\title{
Intensive grazing as a threat in protected areas: the need for adaptive management to protect the Critically Endangered Crau plain grasshopper Prionotropis rhodanica
}

\author{
Linda Bröder, Laurent Tatin, Anja Danielczak \\ Tobias Seibel and Axel Hochirireh
}

\begin{abstract}
Livestock grazing is a key factor in many grassland ecosystems and can substantially influence the conservation of grassland species. The Crau steppe in southern France is a protected area that is traditionally grazed by sheep. The Critically Endangered Crau plain grasshopper Prionotropis rhodanica is endemic to the area and a flagship for the conservation of this unique ecosystem. Its population has declined significantly during the last 2 decades, but the reasons remain poorly understood. One potential factor is an altered habitat structure caused by changes in the grazing regime. We examined the microhabitat preferences of the species and compared the habitat structure of populated sites with those where the species is now extinct (former habitat). We found that populated sites had denser and higher vegetation, whereas former habitat had higher cover of stones and bare ground. Vegetation structure in the habitat of the smallest subpopulation was similar to areas of former habitat, suggesting a marginal habitat quality. Our results show that $P$. rhodanica requires $50-70 \%$ vegetation cover and suggest that grazing has contributed considerably to the population decline, but it remains unclear whether this is a direct effect of habitat degradation or an indirect effect by attracting predators associated with grazing activities. We recommend careful management of grazing to improve habitat quality, which would also benefit other invertebrates and insectivores. Continued monitoring is required to conserve habitat specialists in protected areas.
\end{abstract}

Keywords Conservation management, Crau plain grasshopper, insect conservation, Mediterranean rangeland, microhabitat structure, Orthoptera, Prionotropis rhodanica, threat analysis

Linda Bröder (Corresponding Author), Anja Danielczak, Tobias Seibel and Axel Hochкirch ${ }^{*}$ Department of Biogeography, Trier University, Universitätsring 15, 54286 Trier, Germany. E-mail linda.broeder@mailbox.org

Laurent TAtiN ${ }^{*}$ Conservatoire d'espaces naturels de Provence-Alpes-Côte d'Azur, Saint Martin de Crau, France

${ }^{*}$ Also at: IUCN SSC Grasshopper Specialist Group, Trier, Germany

Received 5 September 2017. Revision requested 24 November 2017.

Accepted 18 January 2018. First published online 10 October 2018.
Supplementary material for this article is available at https://doi.org/10.1017/So030605318000170

\section{Introduction}

T ivestock grazing has a long tradition in grassland eco1 systems (Poschlod, 2015) and traditional, low-intensity grazing plays a key role in biodiversity conservation (Metera et al., 2010), but it can be difficult to achieve the right balance between conservation and socio-economic requirements (WallisDeVries, 2016). There are numerous ways of manipulating grazing intensity and patterns, such as through the choice of livestock species, stocking rate and rotational grazing, and scientific studies (Bermejo et al., 2012) are essential for understanding the processes affecting grazing systems, developing suitable monitoring methods, and implementing sustainable grazing management in protected areas (Christensen et al., 1996). Many protected areas, however, are not subject to scientific monitoring. In the Crau steppe in southern France, which is traditionally grazed by sheep (Badan et al., 1995), neither the past nor the recent dynamics of pastoralism have been documented in detail, even though the Provence region is the second most important for livestock production in the country $(576,000$ sheep; FranceAgriMer, 2013). Although habitat destruction and fragmentation are the main threats to biodiversity in the Crau steppe, lack of knowledge regarding the history of grazing contributes to the risk of inappropriate management of this unique ecosystem.

The Crau plain grasshopper Prionotropis rhodanica is a large (females $45 \mathrm{~mm}$, males $31 \mathrm{~mm}$ body length) grasshopper species that is endemic to the Crau steppe and has become a flagship for conservation in this area. It is a habitat specialist adapted to the unique vegetation type Coussouls, a plant community characterized by Asphodelus fistulosus, Brachypodium retusum, Stipa capillata, Thymus vulgaris and Asphodelus ayardii (Tatin et al., 2013b). The Crau plain grasshopper is protected in France and categorized as Critically Endangered on the IUCN Red List (Hochkirch \& Tatin, 2016). It was formerly widely distributed in the Crau steppe, but has lost large parts of its habitat as a result of conversion into industrial areas or farmland (Foucart \& 
Lecoq, 1998). In the early 2000 s the species was still distributed throughout the Réserve naturelle nationale des Coussouls de Crau (Hochkirch et al., 2014), but has declined dramatically since then, without any obvious changes of the habitat. Only three separated subpopulations currently remain, exposing the species to a high risk of extinction. A strategic conservation plan was developed in 2014 (Hochkirch et al., 2014), including research objectives, conservation management (in situ management and ex situ breeding) and awareness raising. One major goal is to identify the threats that have led to the recent population decline. Because many grasshoppers require a specific vegetation structure (Sänger, 1977) it has been hypothesized that structural vegetation changes may have led to habitat deterioration. Vegetation that is too high and too dense could hinder the locomotion of $P$. rhodanica, reduce availability of oviposition sites and be detrimental for egg development because of cooler microclimatic conditions, whereas vegetation that is too low or too sparse may facilitate predation and increase the risk of desiccation for eggs.

Sheep grazing could be linked to the population decline because it affects vegetation structure. Given that the history and dynamics of pastoralism have not been documented in detail, it is difficult to reconstruct temporal or spatial changes of grazing intensity and the associated impact on the habitat. We therefore tested the hypothesis that changes of the microhabitat structure caused the local extinction of $P$. rhodanica by (1) determining the microhabitat preferences of the species and (2) examining structural differences between populated sites and those where the species is now extinct (former habitat).

\section{Study area}

The $600 \mathrm{~km}^{2}$ Crau plain, located between Marseille, Montpellier and Avignon, has its origin as the ancient delta of the river Durance and is characterized by a short herbaceous plant cover and patches of bare ground and stones (Colomb \& Roux, 1978). Sheep grazing has a long tradition in the Crau (Badan et al., 1995), with currently c. 40,000 sheep grazing from February or March until mid to late June. Most grazed areas are nationally protected as part of the Réserve naturelle nationale des Coussouls de Crau (Fig. 1). Pastoral agriculture in the Crau is organized in 68 pasture zones, managed by shepherds without any restrictions imposed by the Reserve, leading to varying grazing pressure within the area.

The three remaining populations of $P$. rhodanica are referred to by the names of their locations (pasture zone or owner): Peau de Meau, Calissane and BMW (Bayerische Motoren Werke; see below). The 150 ha Peau de Meau pasture zone has the highest mean grazing intensity of the three sites: measured by the number of sheep in the area multiplied by the seasonal number of grazing days and expressed per ha, Peau de Meau had 475 sheep-days/ha. From the 1960 s to the early 1980 os parts of this pasture zone were cultivated as cropland. Peau de Meau is the only population remaining in the centre of the Crau and is located within the Reserve. It is probably a remnant of a formerly large population, but is now restricted to an area of c. 9 ha, with a low population size (LB, LT, AH, A. Schuld \& A. Besnard, unpubl. data). In spring 2015 and 2016, when nymphs and adult Crau plain grasshoppers were present (mid Aprilearly July), the populated area of the Peau de Meau zone was fenced to exclude it from grazing and avoid predation by cattle egrets Bubulcus ibis, which often accompany sheep flocks and are a potential threat to the species (Hochkirch et al., 2014). The 300 ha Calissane zone harbours the largest remaining population and lies mainly within the Reserve, with the exception of 40 ha owned by the French Military. Grazing pressure is low in this area (mean $=177$ sheep-days/ha). The BMW site is owned by Bayerische Motoren Werke AG and surrounded by a high wall. The remaining Coussouls habitat is extremely limited and the two BMW subpopulations are found inside automobile proving grounds. Because of access limitations, we used only one of them as a study site (40 ha). This area had not been grazed for 6-10 years, but grazing was reintroduced in winter 2015/2016 to improve habitat conditions.

To test if changes in habitat structure could be responsible for the disappearance of the species in large parts of its former range, we compared the habitat conditions of the populated sites with three sites where the species went extinct during the last decade (indicated by the prefix EX). These former habitats are in the central part of the Crau where the grasshopper had previously been recorded (Hochkirch et al., 2014), including a part of Peau de Meau (EX-Peau de Meau), Grosse du Levant (EX-Grosse du Levant) and Couloubris (EX-Couloubris). The population in the latter area went extinct recently, with the species having last been recorded there in 2012 .

\section{Methods}

\section{Data collection}

We applied the method proposed by Gröning et al. (2007) to test for microhabitat preferences of the grasshopper. Fieldwork was carried out during the adult phase of the species and each population was tested within one season (Calissane: 3 June-5 July 2013; Peau de Meau: 1 June-10 July 2015; BMW: 3 June-6 July 2016). We recorded data within circular sample patches with a diameter of $30 \mathrm{~cm}$ around each grasshopper we detected. For each individual we recorded date, time, sex, substrate on which the insect perched (stones, bare ground, green vegetation or dry 


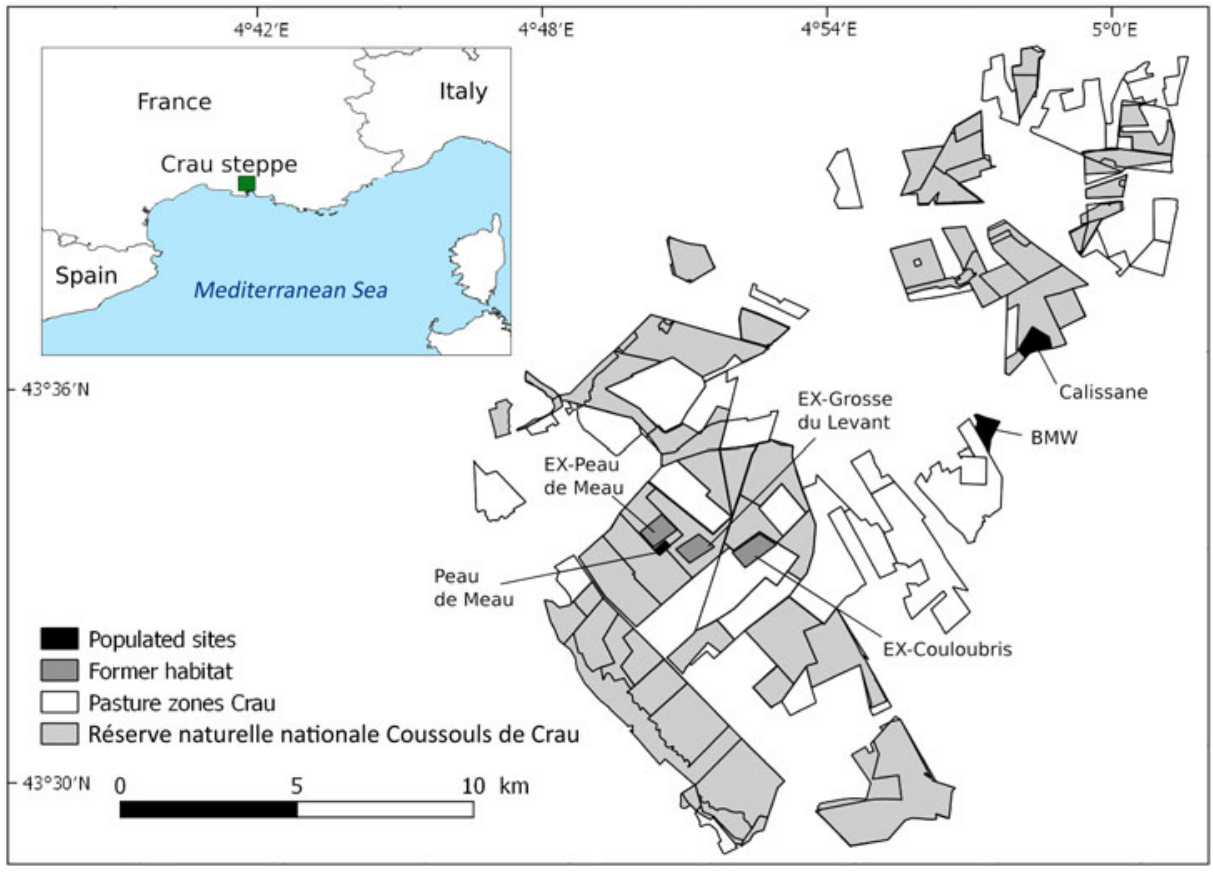

FIG. 1 Map showing the traditional pasture zones of the Crau steppe, the Réserve naturelle nationale Coussouls de Crau, the location of the three remaining populations (Calissane, BMW and Peau de Meau) and the former habitats (EX-Grosse du Levant, EX-Couloubris and EX-Peau de Meau). vegetation/leaf litter) and the temperature of the substrate, measured with an infrared thermometer PeakTech 4990 (PeakTech, Ahrensburg, Germany). We measured the mean and maximum height of the vegetation surrounding the insect and estimated the cover of each substrate type in $10 \%$ steps. We recorded the position of each grasshopper with a differential GPS and marked each specimen with a permanent paint marker to ensure that each individual was sampled only once. To test if the grasshopper actively chose a particular microhabitat within the available habitat structure we recorded the same parameters in a control patch for each individual. The control location was at a distance of $5 \mathrm{~m}$ from the recorded individual, in a random direction (which was chosen by the current position of the second hand of the observer's wristwatch). The distance was chosen to ensure that the control represented the same general habitat type and was accessible by the individual (but not chosen as a microhabitat). For Peau de Meau the control sampling was adjusted because the area was very small, which increases the risk of pseudo-replication and spatial autocorrelation. Therefore, the positions of 50 sample sites were defined in advance by generating random points with a minimum allowed distance of $7 \mathrm{~m}$ in ArcGIS 10.1 (Esri, Redlands, USA).

We amended our data collection procedure between the years based on previous results. During the first study year (2013) we recorded data within a circle with a diameter of $50 \mathrm{~cm}$. However, a first analysis of the data generated no significant results. We concluded that this scale could be too large to detect small-scale heterogeneity, and adjusted the diameter of the circle to $30 \mathrm{~cm}$ in the following years. Although this does not change the mean values measured, it may affect variance. In 2015, the substrate categories green vegetation and dry vegetation/leaf litter were merged into a single parameter, vegetation. All data were recorded using CyberTracker 3.403 (Liebenberg et al., 2017). To compare populated sites and former habitat, we recorded the same habitat parameters as for the microhabitat preferences at 50 positions, which were randomly generated with $A r c G I S$, for each currently populated and former habitat site. We carried out fieldwork during 20 May-1 July 2016, with 10 points sampled per site each week.

\section{Analysis}

We used one-way ANOVAs to compare the microhabitat variables of males and females. Data were Box-Coxtransformed if necessary using Venables and Ripley's MASS library for $R$ (Venables \& Ripley, 2002) to fit them to the models' assumptions by identifying the optimal exponent $\lambda$. Because there were no intersexual differences, we subsequently analysed the data as a single data set. For the Calissane and BMW populations, microhabitat variables were compared to the respective control samples with paired $t$ tests. We carried out one-way ANOVAs for the Peau de Meau population, where control samples were obtained by different methods and were not paired. We used one-way ANOVAs to compare the microhabitat data between the three populations and analysed intersexual differences in utilized substrate type with $\chi^{2}$ tests. We also used $\chi^{2}$ tests for comparing the occupied substrate with its relative frequency in the habitat or the control.

Comparisons between the populated sites (BMW, Calissane, Peau de Meau) and former habitats (EX-Peau 
de Meau, EX-Grosse du Levant, EX-Couloubris) were made with two-level nested ANOVAs, with three sites nested in each group. Hence, we tested whether the mean values of the variables differed between the two groups (populated vs former sites) and between the sites within each group. A Tukey test was used post-hoc for identifying differences between the sites by multiple comparisons. A principal component analysis (PCA) was performed in the vegan 2.4-1 package for $R$ (Oksanen et al., 2016) to illustrate potential intercorrelations of habitat variables. Because of the different units of the variables (\% cover, $\mathrm{cm}$ and ${ }^{\circ} \mathrm{C}$, respectively) the factors were scaled by their proportional eigenvalues. We then applied the function env.fit (environmental fitting) to test for significant correlations of the study sites with the PCA axes using 1,000 permutations. All statistical analyses were carried out in $R \quad 3.2 .3$ (R Development Core Team, 2015).

\section{Results}

\section{Microhabitat preferences}

We obtained microhabitat data for 177 individuals (92 female, 85 male) from Calissane, 32 from Peau de Meau (21 female, 11 male) and 44 from BMW (20 female, 24 male), and found no significant intersexual differences (Supplementary Table 1). Microhabitat variables did not differ significantly between the insects' position and the control samples at Calissane and BMW (Supplementary Table 2), but at Peau de Meau stone cover (52.5\%) was significantly greater and vegetation cover (31.6\%) significantly lower at the $P$. rhodanica locations than at the controls (Table 1, Fig. 2). Microhabitats differed significantly between Calissane, Peau de Meau and BMW in all variables except substrate temperature (Table 1, Supplementary Fig. 1). Grasshoppers at Calissane and Peau de Meau were found significantly more often on stones and bare ground, whereas at BMW they were more often found perching on vegetation (Table 2, Fig. 2).

\section{Comparison of populated and former habitats}

Populated and former habitats differed in all habitat variables except dry vegetation cover and substrate temperature, and all variables differed significantly between sites within the two groups (Table 3). All former habitats and the Peau de Meau site had a relatively high mean stone cover $(34-37 \%$, Fig. 3). By contrast, stone cover at BMW and Calissane was lower (21 and $27 \%$, respectively) and did not differ significantly between these two sites (Supplementary Table 3). The EX-Peau de Meau site had the highest bare ground cover and differed significantly from Peau de Meau and BMW. BMW had a significantly higher
TABLE 1 Results of ANOVAs to test for differences in microhabitat variables between the location of the insect and the control for the population Peau de Meau and between the three populations Calissane, Peau de Meau and BMW (Fig. 1).

\begin{tabular}{|c|c|c|c|c|c|c|}
\hline & \multicolumn{3}{|c|}{$\begin{array}{l}\text { Peau de Meau } \\
\text { (insect location } \\
\text { vs control) }\end{array}$} & \multicolumn{3}{|c|}{$\begin{array}{l}\text { Populations } \\
\text { (comparison of sites) }\end{array}$} \\
\hline & $\lambda^{1}$ & $F_{1,80}$ & $\mathrm{P}$ & $\lambda$ & $F_{2,250}$ & $\mathrm{P}$ \\
\hline Stones & 1 & 6.94 & 0.010 & 0.65 & 49.88 & $<0.001$ \\
\hline Bare ground & 0.58 & 0.18 & 0.674 & 0.44 & 19.94 & $<0.001$ \\
\hline Vegetation & 0.42 & 5.27 & 0.024 & 1.15 & 69.33 & $<0.001$ \\
\hline $\begin{array}{l}\text { Maximum vege- } \\
\text { tation height }\end{array}$ & 0.16 & 0.25 & 0.620 & 0.44 & 159.10 & $<0.001$ \\
\hline $\begin{array}{l}\text { Substrate } \\
\text { temperature }\end{array}$ & 0.08 & 0.39 & 0.532 & 0.61 & $1.25^{2}$ & 0.29 \\
\hline
\end{tabular}

${ }^{1}$ Transformation exponent.

${ }^{2} 248$ residual degrees of freedom.

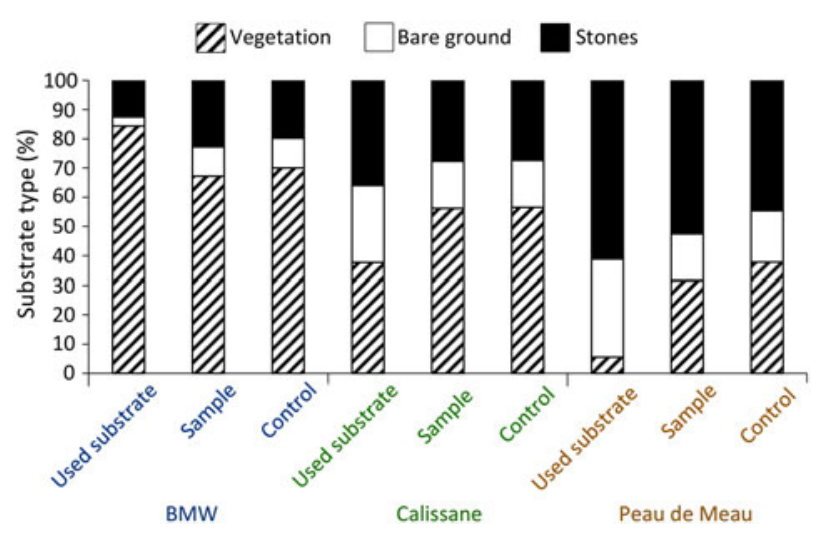

Fig. 2 Relative frequency of substrate types on which the individuals perched (used substrate), of the respective substrates available in the individuals perimeter (sample) and of the control sample (control) for the three study sites (BMW, Calissane, Peau de Meau).

TABLE 2 Results of the $\chi^{2}$ test on differences in the substrate between the sexes and in comparison to the relative frequency of the substrates in the microhabitat (sample) or control.

\begin{tabular}{|c|c|c|c|c|c|c|}
\hline & \multicolumn{2}{|c|}{ Calissane } & \multicolumn{2}{|c|}{ Peau de Meau } & \multicolumn{2}{|c|}{ BMW } \\
\hline & $\chi^{2}$ & $\mathrm{P}$ & $\chi^{2}$ & $\mathrm{P}$ & $\chi^{2}$ & $\mathrm{P}$ \\
\hline Sex & 3.19 & 0.203 & 4.32 & 0.116 & 0.85 & 0.655 \\
\hline $\begin{array}{l}\text { Substrate vs } \\
\text { sample }\end{array}$ & 7.14 & 0.028 & 25.00 & $<0.001$ & 8.51 & 0.014 \\
\hline $\begin{array}{l}\text { Substrate vs } \\
\text { control }\end{array}$ & 7.36 & 0.025 & 31.41 & $<0.001$ & 6.76 & 0.034 \\
\hline
\end{tabular}

vegetation cover (including green and dry vegetation) than all other sites, whereas EX-Peau de Meau had a significantly lower cover of green vegetation than all other sites, except EX-Grosse du Levant. The maximum and mean vegetation 
TABLE 3 Results of the two-level nested ANOVAs. Site (six sites) nested in type (populated sites vs former habitats). Populated sites: BMW, Calissane, Peau de Meau; former habitats: EX-Couloubris, EX-Grosse du Levant, EX-Peau de Meau.

\begin{tabular}{lrrrrrrr}
\hline & \multicolumn{3}{l}{ Type } & & \multicolumn{2}{c}{ Type: Site } \\
\cline { 2 - 3 } & $\lambda^{*}$ & $F_{1,288}$ & $\mathrm{P}$ & & $F_{4,288}$ & $\mathrm{P}$ \\
\hline Stones & 0.59 & 28.88 & $<0.001$ & & 7.70 & $<0.001$ \\
Bare ground & 0.26 & 16.82 & $<0.001$ & 7.78 & 0.007 \\
Vegetation & 0.67 & 49.12 & $<0.001$ & 8.18 & $<0.001$ \\
Green vegetation & 0.54 & 32.89 & $<0.001$ & 22.95 & $<0.001$ \\
Dry vegetation & 0.52 & 2.95 & 0.087 & 2.41 & 0.011 \\
Maximum vegetation & 0.15 & 72.61 & $<0.001$ & 31.18 & $<0.001$ \\
height & & & & & \\
Mean vegetation height & 0.55 & 59.72 & $<0.001$ & 34.35 & $<0.001$ \\
Substrate temperature & 0.66 & 0.61 & 0.436 & 3.46 & 0.010 \\
\hline
\end{tabular}

*Transformation exponent.

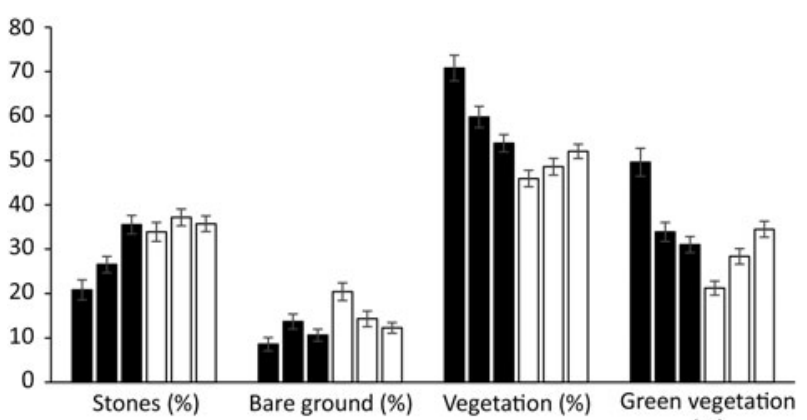
(\%)

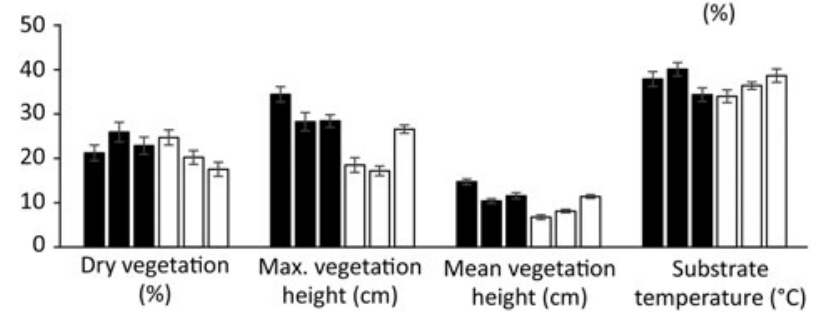

FIG. 3 Means \pm SE of the microhabitat variables of the populated sites (black) BMW, Calissane, Peau de Meau (in this order from left to right), and former habitats (white) EX-Peau de Meau, EX-Grosse du Levant and EX-Couloubris (in this order from left to right).

height was lowest on EX-Peau de Meau and EX-Grosse du Levant, and mean vegetation height was highest at BMW. Peau de Meau and EX-Couloubris were not significantly different in any variable.

The first two principal components of the PCA explained $52 \%$ of the variance (Fig. 4 ). The first component was mainly explained by green vegetation cover (score: 2.06 ), mean (2.09) and maximum vegetation height (1.82), the second component was mainly explained by stone cover $(-2.16)$ and dry vegetation cover (1.80). The parameters associated with the vegetation (vegetation cover, maximum and mean vegetation height) correlated strongly with each other. All sites except Peau de Meau correlated significantly with the
PCA components (environmental fitting; BMW, EX-Peau de Meau, EX-Grosse du Levant: $\mathrm{P}<0.001$; EX-Couloubris: $\mathrm{P}=0.006$; Calissane: $\mathrm{P}=0.013$ ). The strong correlation of BMW with the PCA was associated with the first principal component. EX-Peau de Meau and EX-Grosse du Levant correlated negatively with the first principal component, as these sites had a relatively low vegetation height and low vegetation cover. The Peau de Meau and EXCouloubris vectors grouped together along the second principal component.

\section{Discussion}

Intensive grazing as a threat

Our key hypothesis was that changes in vegetation structure caused by alterations in the grazing regime have led to a degradation of the Crau plain grasshopper's habitat, followed by the local extinction of the animals in some areas. Our results show that the three populated sites had denser and higher vegetation, whereas the sites where the species went extinct had a higher cover of bare ground and stones. The Peau de Meau site was the one most similar to former habitats, but this population probably experienced a considerable decline in recent years and may be close to extinction. This site has also been used as farmland, leading to topsoil degradation and thus different vegetation and stone cover compared to the other sites. Calissane and BMW, where the microhabitat parameters measured at the insects' locations did not differ from the controls, generally appear to provide a suitable habitat structure for the grasshopper. Both sites had the highest vegetation densities and lowest stone cover.

The PCA illustrates that the sites can be ranked according to their population status along a gradient of vegetation structure and stone cover: (1) BMW and Calissane maintain intact populations and have an intermediate vegetation density and a low stone cover, (2) Peau de Meau and EX-Couloubris can be considered as transition sites (close to extinction or recently extinct) with less vegetation and high stone cover, (3) EX-Peau de Meau and EX-Grosse du Levant provide no suitable habitat, which may have favoured the extinction of the species at these locations (both sites have scarce and low vegetation but a high stone cover). Overall, the results suggest that the Crau plain grasshopper requires an intermediate vegetation density (50-70\% cover). Given that temperature was similar at all populated sites, it is likely that vegetation is needed to provide a suitable microclimate, but it may also provide food and shelter against predators and harsh meteorological conditions.

Foucart \& Lecoq (1996) observed that P. rhodanica often hides between stones, but also inside tufts of grass. In our study the grasshoppers were predominantly detected on 


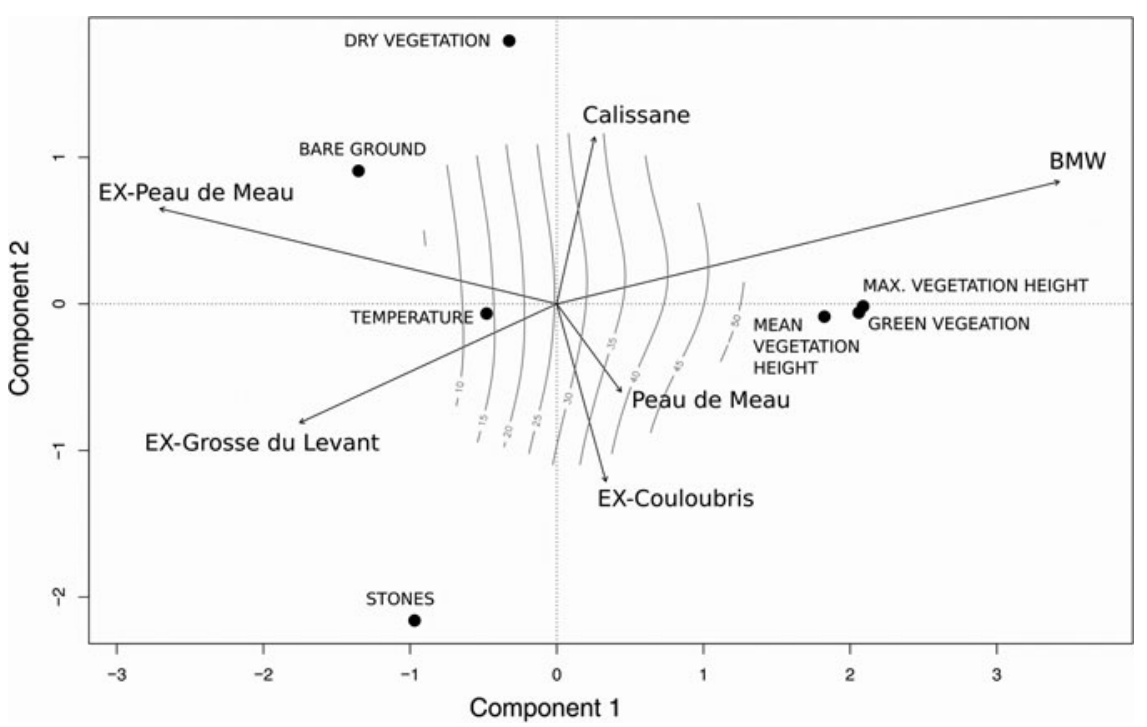

FIG. 4 Plot of the first two components of the principal component analyses (PCA) of the microhabitat variables, explaining $52 \%$ of the total variance. Arrows indicate the correlation of the study sites using environmental fitting. The isoclines illustrate maximum vegetation height along the two functions. stones and bare ground in Calissane and Peau de Meau, whereas at BMW they were found more often on vegetation. A preference for stones may be related to the camouflage provided by the stone-like colouring of the species, but loss of vegetation cover could nevertheless increase predation risk. Populations of some potential predators (insectivorous birds, particularly lesser kestrel Falco naumanni and cattle egret) had been low in the Crau steppe before, but have increased during the last two decades, and predation by birds has therefore been identified as a potential threat to the Crau plain grasshopper (Hochkirch et al., 2014).

\section{Conservation management}

Grazing by sheep is a traditional land use in the Crau region and changes in vegetation structure have probably occurred frequently in the past. However, differences in vegetation structure between populated sites and former habitats suggest that grazing could have caused the decline of the Crau plain grasshopper, which means that (at least for this species) the local grazing regime must be considered as overgrazing. It remains uncertain whether the decline is a direct effect of habitat degradation or an indirect effect of grazing (e.g. by attracting predators such as the cattle egret).

Sheep grazing has been largely unmanaged by the Reserve and poorly monitored. Adapting the grazing system to benefit biodiversity conservation and improve habitat will be crucial to protect $P$. rhodanica and other species. Foucart \& Lecoq (1998) considered traditional (low-intensity) grazing to be beneficial for $P$. rhodanica because it helps to maintain habitat conditions and Fadda et al. (2008) proposed reducing grazing intensity in the Crau steppe to foster beetle diversity. Population trends of other invertebrate species in the Crau region are largely unknown and population declines probably not recognized. Because grasshoppers are an important food source for many other animals, their decrease could negatively affect threatened insectivorous bird species such as the protected stone curlew Burhinus oedicnemus (Dennis et al., 2008) or reptiles, e.g. the ocellated lizard Timon lepidus (Tatin et al., 2013a).

Contrary to intensive grazing in the centre of the Crau steppe, abandonment may represent a threat on the BMW site, which had not been grazed over a period of 6-10 years. Even though plant succession in the Crau steppe is slow compared to other Mediterranean ecosystems (Fadda et al., 2008) the site had the highest vegetation cover (70.8\%). Our study shows that site-specific management is required: grazing intensity needs to be reduced in the centre of the nature reserve to restore vegetation cover, and winter/ early spring grazing needs to be conducted on the BMW site to avoid habitat deterioration. The latter has recently been reintroduced, at a time before nymphs of the grasshopper hatch, to avoid negative effects of predation by cattle egrets. Grazing is generally required to keep the open character of the ecosystem and for its biota (e.g. steppe birds), and socioeconomic consequences of changes in the grazing regime also need to be considered. Overall, adaptive management and monitoring of different organism groups are needed to avoid negative effects on threatened species.

The grasshopper population at Calissane, where neither over- nor undergrazing occur, is by far the largest. This site represents the optimal habitat for $P$. rhodanica and can serve as a reference for choosing appropriate sites for the planned reintroduction of the species in other areas of the Crau steppe (Hochkirch et al., 2014). This approach is important because the Crau plain grasshopper does not move over large distances and thus cannot recolonize suitable habitat rapidly.

Grazing management is mostly discussed in the context of the ecological requirements of mammals and birds (Johnston \& Anthony, 2008; Pakanen et al., 2011). 
However, the results of our study and those of others (Fonderflick et al., 2014; Lázaro et al., 2016) highlight the need for appropriate grazing management for insects. This is particularly urgent as recent analyses show that insects are under considerable threat (Dirzo et al., 2014). Many insect species have small distributional ranges and are thus vulnerable to anthropogenic changes to their environment (Hochkirch et al., 2016). Preserving these species is only possible with a sound knowledge of their ecology and the threats affecting them.

\section{Conclusion}

Our study suggests that changes in vegetation structure have played an important role in the decline of the Crau plain grasshopper. The comparison of populated sites and former habitats reveals major structural changes in vegetation, probably caused by increased grazing in the centre of the Crau steppe. There are no detailed data on past grazing dynamics, but remote sensing data could help to reconstruct changes in vegetation cover. Further research into the habitat preferences of other life stages (eggs, nymphs) and studies of other possible threats, particularly the role of predation by birds, are necessary. Our study illustrates that occurrence within a protected area does not necessarily save a species from extinction. Adaptive habitat management and monitoring of population trends of threatened species are required to preserve biodiversity within protected areas.

Acknowledgments The survey was funded by grants of the Mohamed bin Zayed Species Conservation Fund (project number 142510206), the Studienstiftung des deutschen Volkes, the EU programme ERASMUS+ via the German Academic Exchange Service (DAAD) and the Direction Regionale de l'environnement de l'aménagement et du logement de Provence Alpes-Côte d'Azur. We thank Antoine Foucart (Centre de coopération internationale en recherche agronomique pour le développement) for his advice, Andreas Schuld and Jens Schmitt for help with data collection and analysis, the Conservatoire d'espaces naturels de Provence-Alpes-Côte d'Azur (CEN PACA) and its team for support during fieldwork, and Trier University for providing equipment.

Author contributions Conception of the study, drafting of text: $\mathrm{LB}$, $\mathrm{AH}$ and LT; data collection: $\mathrm{LB}, \mathrm{AD}$ and TS; writing: $\mathrm{LB}, \mathrm{AH}$ and LT; data analysis and interpretation, revision of text: all authors.

\section{Conflicts of interest None.}

Ethical standards Our research had the necessary approvals and permits from the Direction Départementale du Territoire et de la Mer (DDTM13). The study was performed in collaboration between Trier University (Germany) and the Conservatoire d'espaces naturels de Provence-Alpes-Côte d'Azur (France, host country). Data and results are shared equally and the reserve management (represented by the co-author Laurent Tatin) contributed to the research. We strictly respected all rules and regulations of the host country. Our research was part of the implementation of the conservation strategy for this species, which has followed the IUCN handbook for species conservation planning and was drafted in cooperation with the IUCN SSC Species Conservation Planning Subcommittee and the IUCN SSC Invertebrate Conservation Subcommittee. No animals were collected or killed during this study.

\section{References}

BADAn, O., Congés, G. \& BRUn, J.-P. (1995) Les bergeries romaines de la Crau d'Arles. Les origines de la transhumance en Provence. Gallia, 52, 263-310.

Bermejo, L.A., de Nascimento, L., Mata, J., Fernández-Lugo, S., CAmacho, A. \& ARÉVAlo, J.R. (2012) Responses of plant functional groups in grazed and abandoned areas of a natural protected area. Basic and Applied Ecology, 13, 312-318.

Christensen, N.L., Bartuska, A.M., Brown, J.H., Carpenter, S., D’Antonio, C., Francis, R. et al. (1996) The report of the ecological society of America committee on the scientific basis for ecosystem management. Ecological Applications, 6, 665-691.

Colomb, E. \& Roux, R.M. (1978) La Crau, données nouvelles et interprétations. Géologie Méditerranéenne, 5, 303-324.

Dennis, P., Skartveit, J., McCracken, D.I., Pakeman, R.J., Beaton, K., Kunaver, A. \& Evans, D.M. (2008) The effects of livestock grazing on foliar arthropods associated with bird diet in upland grasslands of Scotland. Journal of Applied Ecology, 45, 279-287.

Dirzo, R., Young, H.S., Galetti, M., Ceballos, G., Isaac, N.J.B. \& Collen, B. (2014) Defaunation in the Anthropocene. Science, 345, 401-406.

Fadda, S., Henry, F., Orgeas, J., Ponel, P., Buisson, E. \& Dutoit, T. (2008) Consequences of the cessation of 3000 years of grazing on dry Mediterranean grassland ground-active beetle assemblages. Comptes Rendus Biologies, 331, 532-546.

Fonderflick, J., Besnard, A., Beuret, A., Dalmais, M. \& Schatz, B. (2014) The impact of grazing management on Orthoptera abundance varies over the season in Mediterranean steppe-like grassland. Acta Oecologica, 6o, 7-16.

Foucart, A. \& Lecoq, M. (1996) Biologie et dynamique de Prionotropis hystrix rhodanica Uvarov, 1923, dans la plaine de la Crau (France) (Orthoptera, Pamphagidae). Bulletin de la Société Entomologique de France, 101, 75-87.

Foucart, A. \& Lecoq, M. (1998) Major threats to a protected grasshopper, Prionotropis hystrix rhodanica (Orthoptera, Pamphagidae, Akicerinae), endemic to southern France. Journal of Insect Conservation, 2, 187-193.

France A griMer (2013) Les filières de l'élevage français. Http://www. franceagrimer.fr/content/download/21788/178234/file/plaquette\% 2odes\%2ochiffres\%20cl\%C3\%A9sBD2.pdf [accessed 13 March 2017].

Gröning, J., Krause, S. \& Hochkirch, A. (2007) Habitat preferences of an endangered insect species, Cepero's ground-hopper (Tetrix ceperoi). Ecological Research, 22, 767-773.

Hochkirch, a. \& Tatin, L. (2016) Prionotropis rhodanica. The IUCN Red List of Threatened Species 2016. Http://dx.doi.org/10.2305/IUCN. UK.2016-3.RLTS.T15038481A47713628.en [accessed 17 February 2017].

Hochkirch, A., Tatin, L. \& Stanley Price, M. (2014) Crau Plain Grasshopper, a Strategy for its Conservation 2015-2020. IUCN-SSC \& CEN PACA, Saint-Martin-de-Crau, France.

Hochkirch, A., Nieto, A., Criado, M.G., Cálix, M., Braud, Y., Buzzetti, F.M. et al. (2016) European Red List of Grasshoppers, 
Crickets and Bush-Crickets. Publications Office of the European Union, Luxembourg City, Luxembourg.

Johnston, A.N. \& Anthony, R.G. (2008) Small-mammal microhabitat associations and response to grazing in Oregon. Journal of Wildlife Management, 72, 1736-1746.

Liebenberg, L., Steventon, J., Brahman, N., Benadie, K., Minye, J., Langwane, H. \& Xhukwe, Q. (2017) Smartphone icon user interface design for non-literate trackers and its implications for an inclusive citizen science. Biological Conservation, 208, 155-162.

Lázaro, A., Tscheulin, T., Devalez, J., Nakas, G. \& Petanidou, T. (2016) Effects of grazing intensity on pollinator abundance and diversity, and on pollination services. Ecological Entomology, 41, 400-412.

Metera, E., Sakowski, T., SŁoniewski, K. \& Romanowicz, B. (2010) Grazing as a tool to maintain biodiversity of grassland-a review. Animal Science Papers and Reports, 28, 315-334.

Oksanen, J., Blanchet, F.G., Friendly, M., Kindt, R., Legendre, P., McGlinn, D. et al. (2016) Vegan: Community Ecology Package. Https:/CRAN.R-project.org/package=vegan [accessed 20 December 2016].

Pakanen, V.-M., Luukronen, A. \& Koivula, K. (2011) Nest predation and trampling as management risks in grazed coastal meadows. Biodiversity and Conservation, 20, 2057-2073.
Poschlod, P. (2015) The origin and development of the Central European man-made landscape, habitat and species diversity as affected by climate and its changes-a review. Interdisciplinaria Archaeologica - Natural Sciences in Archaeology, 6, 197-221.

R Development Core Team (2015) A language and environment for statistical computing. R Foundation for Statistical Computing, Vienna, Austria. Https://www.R-project.org/ [accessed 27 December 2015].

SÄNGER, K. (1977) Über die Beziehungen zwischen Heuschrecken (Orthoptera; Saltatoria) und der Raumstruktur ihrer Habitate. Zoologische Jahrbücher: Abteilung für Systematik, Ökologie und Geographie der Tiere, 104, 433-488.

Tatin, L., Chapelin-Viscardi, J.-D., Renet, J., Becker, E. \& Ponel, P. (2013a) Diet pattern and variations of ocellated lizard Timon lepidus in a Mediterranean steppe area (Crau plain, France). La Terre et la Vie (Revue d'Écologie), 68, 47-58.

Tatin, L., Wolff, A., Boutin, J., Colliot, E. \& Dutoit, T. (2013b) Écologie et Conservation d'une Steppe Méditerranéenne: La plaine de Crau. Editions Quae, Versailles, France.

Venables, W.N. \& Ripley, B.D. (2002) Modern Applied Statistics with S-Plus. Springer, New York, USA.

WAllis DeVRIEs, M.F. (2016) Grazing and biodiversity: from selective foraging to wildlife habitats. Options Méditerranéennes, Series A:

Mediterranean Seminars, 116, 177-187. 